\title{
Kata - The true essence of Budo martial arts?
}

\author{
Simon DODD*, \& David BROWN \\ Cardiff Metropolitan University (Wales)
}

5th IMACSSS World Scientific Congress Abstracts, Rio Maior (Portugal), October 6-8

Section: Historical, sociological and philosophical issues of MA\&CS

Type: Oral communication

\section{Introduction}

Kata is a common pedagogy found throughout Japanese society and is particularly prevalent in the Japanese martial arts. Kata has become an internationally recognised symbol for the Japanese approach to teaching, learning and creativity and has been referred to as "a pattern structure of the Japanese society and culture in general" (Rafolt, 2014, p.199). Despite a long lineage, as a cornerstone of Japanese social pedagogy kata has endured and continued to evolve, however there is still contention as to the relevance of kata as a pedagogy (particularly outside Japan), often due to the sociocultural context not being fully understood. This paper analyses the historical and spiritual developments of bushido, followed by the social changes that transitioned bujutsu into budo. Next, the relevant position of kata in budo martial arts is explored and the use of kata as a pedagogy is discussed. Finally, repositioning kata in light of the contextual expansion, we demonstrate how kata could represent the intended essence of budo as well a culturally valued, spiritual pedagogy.

\section{Methodology}

This paper is informed by an interpretive paradigmatic view, the methodology for which utilises documentary analysis techniques including hermeneutics (Kuckartz, 2014), qualitative content analysis (Forman \& Damschroder, 2007; Kuckartz, 2014), and grounded theory (Glaser \& Strauss, 1967; Strauss \& Corbin, 1998). Drawing on existing sources of information, starting with the original texts of the founders of the martial arts commonly practiced today, and branching out into other historical, academic, and practitioner resources, it was possible to develop a multilayered analysis of the social and cultural developments of kata. Cross-analysis in this manner allowed for a contextual expansion of the developments that led to the use of kata as a fundamental martial, and spiritual, pedagogy.

\section{Results}

It was found that the spiritual influences on/of Bushido have continued to inform the martial practices that continue to emerge from Japan to this day. The principles of Bujutsu, and the later budo, martial arts were found to be deeply rooted in spiritual ideologies from Buddhism, Shintoism, and Confucianism. This was most profoundly noticed in the preoccupation with the study, and acceptance, of death that was said to free a warrior's mind to allow them to become positive moral and social agents. Thorough analysis found that socio-political developments in Japan led to bujutsu being seen as an anachronistic legacy of the ruling samurai class, and so a greater emphasis was placed on the spiritual and moral developments of practitioners that would become the modern pursuit of budo martial arts. It was felt that this philosophical shift is what heralded the use of kata as the principle training method in most budo martial arts. Kata was found to represent a physically learned embodiment of the moral and social principles of each martial art, and through repetition

*Email: $\underline{\text { sdodd@ @ardiffmet.ac.uk }}$ 
and imitation also constitutes a link to the historical combative lineage of bujutsu. Further, the lineage implied a spiritual connection to the origins of bushido that became evident from the sacrilisation of the practice. Reporting the significant differences between Eastern and Western cultural views on creativity and learning found that kata as pedagogy is prone to misunderstanding when the cultural outlook is not acknowledged.

\section{Discussion and conclusion}

Analysis found that a failure to recognise the sociocultural setting of kata's origin has led to kata based training being afforded less importance in Western practice due to a lack of understanding. It was felt that this failure has led to the cultural purpose of kata, to embody the principles and philosophies of an art, being largely forgotten or mystified by practitioners. We argue that the sociocultural developments of bushido, and the transformation of bujutsu to budo, that placed moral, social and spiritual development at the core of the martial art philosophy intertwines kata with budo practice. As a result of this, we conclude that the pedagogy of kata has become the bodily allusion and expression of the core values of the Japanese arts, and an essential pedagogy of intercultural transmission. This may, therefore, suggest that kata represents the true essence of budo.

\section{References}

Forman, J., \& Damschroder, L. (2007). Qualitative Content Analysis. In L. Jacoby \& L. A. Siminoff (Eds.), Empirical Methods for Bioethics: A Primer (pp. 39-62). Bingley, UK: Emerald Group Publishing Limited.

Glaser, B., \& Strauss, A. (1967). The Discovery of Grounded Theory: Strategies for Qualitative Research. Chicago: Aldine.

Kuckartz, U. (2014). Qualitative Text Analysis: A Guide to Methods, Practice \& Using Software. London: Sage.

Rafolt, L. (2014). Ritual Formalism and the Intangible Body of the Japanese Koryū Budō Culture. Narodna umjetnost: Croatian Journal of Ethnology and Folklore Research, 51(1), 183-208

Strauss, A., \& Corbin, J. (1998). Basics of Qualitative Research: Techniques and Procedures for Developing Grounded Theory (2 ${ }^{\text {nd }}$ ed.). Thousand Oaks, CA: Sage.

Key words: Kata; budo; martial arts; spirituality; pedagogy. 